\title{
Rights : Review
}

An approach to applying Rights Statements from RightsStatements.org

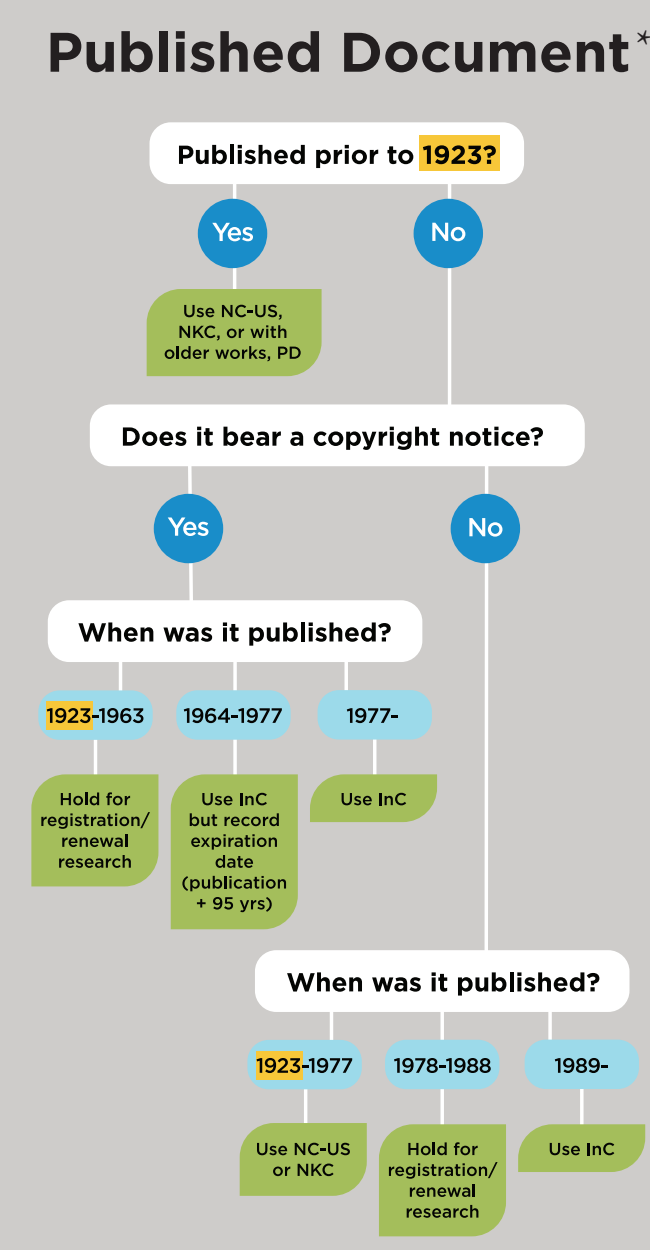

This is an illustration of one possible approach to determining which rights statement to associate with digital object. More than one rights statement may be appropriate for some objects, and organizations may choose among these based on a variety of factors. This illustration is not intended as legal advice.

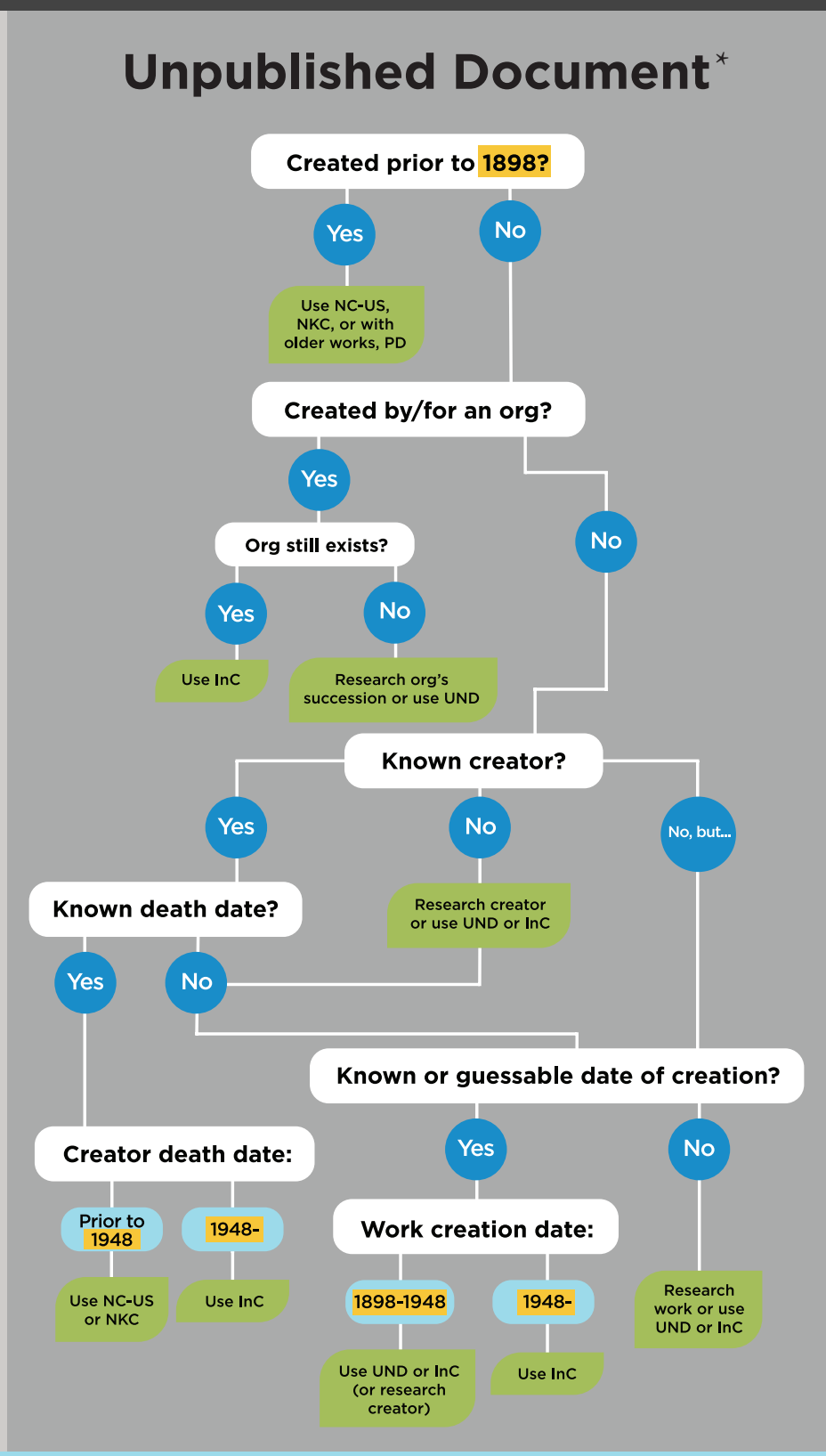

\section{Government Document}

Created by US federal government?
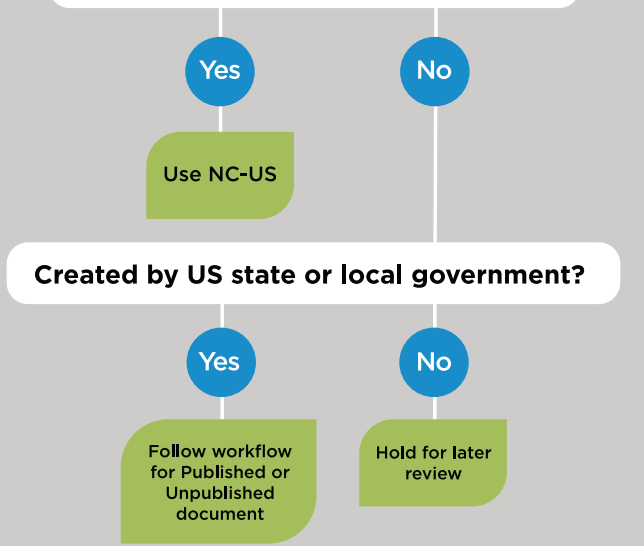

${ }^{*}$ Published or Unpublished?

It's not always obvious whether something should follow the published or unpublished workflow. For example, a seemingly unpublished item may in fact be an earlier instance of a published item, and therefore be under copyright. You should consult with legal and collection-specific experts about withs that may have evolved towards publication.

Rolling Dates are Highlighted

Published prior to $\mathrm{XXXX}$ ? $\quad \mathrm{XXXX-XXXX}$

These dates change on January 1 every year. This is the 2018 version. Please check the latest version of this document at z.umn.edu/rightsreview 